\title{
Article
}

\section{What do measures of patient satisfaction with the doctor tell us?}

Boquiren, Virginia M., Hack, Tom, Beaver, Kinta and Williamson, Susan

Available at http://clok.uclan.ac.uk/12345/

Boquiren, Virginia M., Hack, Tom, Beaver, Kinta ORCID: 0000-0002-6552-2323 and Williamson, Susan ORCID: 0000-0002-9635-4473 (2015) What do measures of patient satisfaction with the doctor tell us? Patient Education and Counseling, 98 (12). pp. 1465-1473. ISSN 07383991

It is advisable to refer to the publisher's version if you intend to cite from the work. http://dx.doi.org/10.1016/j.pec.2015.05.020

For more information about UCLan's research in this area go to http://www.uclan.ac.uk/researchgroups/ and search for <name of research Group>.

For information about Research generally at UCLan please go to http://www.uclan.ac.uk/research/

All outputs in CLoK are protected by Intellectual Property Rights law, including Copyright law. Copyright, IPR and Moral Rights for the works on this site are retained by the individual authors and/or other copyright owners. Terms and conditions for use of this material are defined in the policies page.

\section{CLoK}

Central Lancashire online Knowledge www.clok.uclan.ac.uk

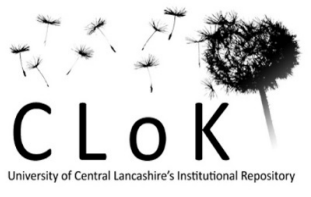




\section{Accepted Manuscript}

Title: What Do Measures of Patient Satisfaction with the Doctor Tell Us?

Author: Virginia M. Boquiren PhD Thomas F. Hack PhD Kinta Beaver RGN PhD Susan Williamson RGN PhD



PII: S0738-3991(15)00264-5

DOI: http://dx.doi.org/doi:10.1016/j.pec.2015.05.020

Reference: PEC 5062

To appear in: Patient Education and Counseling

Received date: $\quad 11-10-2014$

Revised date: 28-5-2015

Accepted date: $\quad 30-5-2015$

Please cite this article as: Boquiren VM, Hack TF, Beaver K, Williamson S, What Do Measures of Patient Satisfaction with the Doctor Tell Us?, Patient Education and Counseling (2015), http://dx.doi.org/10.1016/j.pec.2015.05.020

This is a PDF file of an unedited manuscript that has been accepted for publication. As a service to our customers we are providing this early version of the manuscript. The manuscript will undergo copyediting, typesetting, and review of the resulting proof before it is published in its final form. Please note that during the production process errors may be discovered which could affect the content, and all legal disclaimers that apply to the journal pertain. 
PATIENT SATISFACTION WITH DOCTOR

\section{Research Highlights.}

- Patient satisfaction measures vary greatly in their psychometrics and domains covered.

- Assessment goals will determine the particular patient satisfaction measure to use.

- A multi-dimensional measure is needed, guided by a theoretical framework.

- Five major domains underlie the construct of patient satisfaction with the doctor.

- These domains point to key areas of physician training and quality assessment. 
PATIENT SATISFACTION WITH DOCTOR

\title{
What Do Measures of Patient Satisfaction with the Doctor Tell Us?
}

\author{
Virginia M. Boquiren, $\mathrm{PhD}^{1,2}$, Thomas F. Hack, $\mathrm{PhD}^{2,3}$, Kinta Beaver, RGN PhD ${ }^{3}$, Susan \\ Williamson, RGN PhD ${ }^{3}$
}
${ }^{1}$ Behavioural Sciences \& Health Research Division, University Health Network, Toronto, Ontario, Canada
${ }^{2}$ College of Nursing, Faculty of Health Sciences, University of Manitoba, Winnipeg, Manitoba, Canada
${ }^{3}$ School of Health, University of Central Lancashire, Preston, United Kingdom
Corresponding author at: Virginia M. Boquiren, PhD
Behavioural Sciences \& Health Research Division
University Health Network
9EN-242; 200 Elizabeth St.
Toronto, ON Canada M5G 2C4
(c): +1.647.454.0064; (f): +1.416.340.4739
Email: vboquire@uhnresearch.ca

Author information: Thomas F. Hack, PhD

College of Nursing; Faculty of Health Sciences; University of Manitoba

I.H. Asper Clinical Research Institute

CR3018; 369 Taché Avenue

Winnipeg, MB Canada R2H 2A6

Email: thack@sbrc.ca

Kinta Beaver, RGN PhD

School of Health; University of Central Lancashire

Preston, UK

Email: kbeaver@uclan.ac.uk

Susan Williamson, RGN PhD

School of Health; University of Central Lancashire

Preston, UK

Email: swilliamson2@uclan.ac.uk 
PATIENT SATISFACTION WITH DOCTOR

\section{Abstract.}

Objective: To gain an understanding of how patient satisfaction (PS) with the doctor (PSD) is conceptualized through an empirical review of how it is currently being measured. The content of PS questionnaire items was examined to a) determine the primary domains underlying PSD, and b) summarize the specific doctor-related characteristics and behaviors, and patient-related perceptions, composing each domain.

Methods: A scoping review of empirical articles that assessed PSD published from 2000 to November 2013. MEDLINE and PsycINFO databases were searched.

Results: The literature search yielded 1726 articles, 316 of which fulfilled study inclusion criteria. PSD was realized in one of four health contexts, with questions being embedded in a larger questionnaire that assessed PS with either: 1) overall healthcare, 2) a specific medical encounter, or 3) the healthcare team. In the fourth context, PSD was the questionnaire's sole focus. Five broad domains underlying PSD were revealed: 1) Communication Attributes; 2) Relational Conduct; 3) Technical Skill/Knowledge; 4) Personal Qualities; and 5) Availability/Accessibility.

Conclusions \& Practice Implications: Careful consideration of measurement goals and purposes is necessary when selecting a PSD measure. The five emergent domains underlying PSD point to potential key areas of physician training and foci for quality assessment.

Keywords: patient satisfaction; patient-physician communication; measurement; review 
PATIENT SATISFACTION WITH DOCTOR

\section{List of abbreviations}

PS = patient satisfaction

PSD = patient satisfaction with the doctor 
PATIENT SATISFACTION WITH DOCTOR

\section{Introduction}

Patients' perspectives on their medical treatment experience have received considerable prominence in the evaluation of modern healthcare, with these subjective appraisals being viewed as valuable health outcomes. The growing recognition of patients as legitimate appraisers and savvy medical service users has shaped the evolution of healthcare assessment, planning, delivery, and improvement [1-4]. The development of self-report questionnaires to assess patients' satisfaction with their medical experience has proliferated in response to healthcare providers' increasing demand for this information. Today, patient satisfaction (PS) ratings are important indicators of the efficacy, quality, and feasibility of healthcare services [e.g., 1,4-6].

The avid interest in PS measurement can trace its roots to the consumer movement in the 1960 s, which viewed patients as valuable consumers of healthcare services $[2,7]$. This evolution has continued with a shift from consumerism to a focus on 'patient experience' and the encouragement of patient involvement in their medical care [8-11]. This has ultimately culminated in the present practice mandates of satisfactorily fulfilling the individual's healthcare needs and ensuring quality care $[6,12]$. PS measures have been instrumental in evaluating this objective, and in the current healthcare landscape are being used for two general purposes: 1) Marketing, and 2) Quality Assessment [2,13,14]. From a marketing perspective, maximizing PS can influence patient choice of care provider [15], resulting in significant financial benefits, such as increased profits, capitalizing on government incentives for meeting certain performance standards [e.g., 5,16,17] and service efficiency $[6,18]$. Thus, 
PATIENT SATISFACTION WITH DOCTOR

measuring PS becomes a valuable economic practice for institutions wishing to increase revenue gains through enhanced reputation, positive word-of-mouth [15], and greater patient volume through customer loyalty $[5,19,20]$.

PS measures are also fundamental barometers of perceived quality healthcare, often serving as proxies for level of service caliber [6]. They are often utilized in program evaluation and improvement, and treatment quality monitoring and assurance $[1-3,6,13]$. Many North American and European healthcare agencies have instituted mandatory, regular PS surveys as part of assessing quality care [21]. For example, doctors in the United Kingdom are required to undergo a revalidation process to demonstrate fitness to practice, a process that includes PS surveys [22]. The multidimensional Picker Patient Experience Questionnaire [21] was expressly designed to measure quality of care from the patient's perspective [6]. The inclusion of PS measures in quality assessments of healthcare service underscores the recognition of the importance of the patient experience.

Patient satisfaction with the doctor

It can be argued that patient interactions with healthcare providers, particularly their treating doctor, are fundamental in defining the healthcare experience. Patients' lasting impressions of these interactions influentially determine the degree of satisfaction with medical services received. PS is one fundamental building block to the establishment of a long-term relationship with a specific healthcare provider $[7,23]$. Other notable outcomes associated with PS with the doctor (PSD) include fewer malpractice suits, greater provider loyalty and an increased tendency to recommend that doctor to others [e.g., 15,24]. 
PATIENT SATISFACTION WITH DOCTOR

Given its many benefits, it is not surprising there is considerable interest in investigating contributory factors to PSD. Satisfaction with overall care and the doctor have shown strong associations with the fulfillment of patient expectations regarding the medical experience (e.g., desired treatment outcomes) [e.g., 4,25-27] and personal attitudes about healthcare, the persons and organizations providing the care service [e.g., 12,28,29]. Research on patientrelated determinants of satisfaction generally explores how personality, sociocultural beliefs, and historical experiences with doctors in different contexts impact perceptions of health service quality [28]. Organizational factors include systemic, practice-related issues such as other healthcare staff interactions, ease in getting a clinic appointment, waiting room times, technology and equipment, and access to staff and facilities. While outside the direct medical encounter, these factors have nonetheless been shown to influence patients' evaluations of their doctor [30-31]. Physician-related factors, particularly those concerning communication ability, interpersonal and technical skill, and accessibility, are reported to be of monumental importance to patients [e.g., 26,32-35]. For example, patients describe a "good doctor" as being friendly and empathetic, honest, polite, approachable; one who treats patients with respect. Patients value a doctor who is willing to spend time with them and address all their concerns, who is accessible, who is expertly skilled, and can communicate information in an understandable manner [e.g., 36,37]. Physician personal characteristics and overt behaviors that patients can tangibly witness and experience during the medical interaction significantly contribute to evaluation of that healthcare provider [e.g., 26,38,39]. Measuring patient satisfaction with the doctor 
PATIENT SATISFACTION WITH DOCTOR

The development of measures assessing PSD has been undertaken by numerous research, clinical and organizational sectors, each with their own purpose and use for patient ratings. As a result of these endeavors, there are currently a number of PS assessment tools available that differ in aim, content, and psychometric properties [23]. Variability in these measures can be attributed to many reasons; an important one being the lack of consensus in how PS is defined. A widely cited definition views patient satisfaction as "a health care recipient's reaction to salient aspects of the context, process, and result of their service experience" (pg. 189) [40]. This definition is consistent with many views that PS is a complex and multidimensional construct [e.g., 34,41,42]. In recognition of its multifactorial nature, PSD measures have often been designed to capture several elements of the healthcare experience, particularly different provider characteristics and/or psychosocial factors underlying the doctorpatient interaction. More global measures of PS have also been used, reflecting a more summative evaluation of the patient's experience/perspective on their doctor [23]; e.g., oneitem questions such as "How do you rate your overall satisfaction with your doctor?". This variety of assessment methods has afforded many options when assessing PSD. Depending on the assessor's perspective and goals, the PSD tool will vary in its focus and content.

It is only in this century that we have seen the proliferation of PS measures assessing satisfaction with one's physician. The medical paternalistic approach to healthcare has shifted to a focus on the patient as an important partner in the delivery and evaluation of the quality of care. Organizations (e.g., hospitals, private clinics, insurance companies) are now ethically and legally obligated and accountable; hence, the growing importance of PS measures. Perhaps paralleling the evolution of healthcare systems and delivery, as well as building upon growing 
PATIENT SATISFACTION WITH DOCTOR

knowledge of the PS construct and its determinants, it is conceivable that PSD tools have also evolved, begging the questions: How is PSD being measured today? How are the domains of PSD represented in its measures? Are the doctor attributes and behaviors deemed important by patients reflected in these PS measures?

Aim

The aim of the present study was to gain a better understanding of how the construct of PSD is conceptualized by how it is being currently assessed in healthcare. To accomplish this aim, we examined the content of questionnaire items composing these PS measures in order to: a) determine the primary domains underlying PSD, and b) summarize the specific doctorrelated characteristics and behaviors, and patient-related perceptions, assessed in each domain. Given the exploratory nature of the study and the goal of identifying key concepts, a scoping review of empirical studies that incorporate an assessment of PSD was undertaken. As the study objective involved a broad canvassing of the current literature to research how PSD was being measured, evaluation of the quality of the studies and the psychometric properties of the various assessment tools was not performed, being outside the purview of the review's aims.

\section{Methods}

Literature Search.

The primary focus of the search was to capture literature on the variety of methods by which PSD is assessed. The search for relevant publications was restricted to a time frame of January 2000 - November 2013. In order to obtain the largest scope of topic coverage, the databases MEDLINE and PsycINFO were used for article retrieval. In the MEDLINE search, three 
PATIENT SATISFACTION WITH DOCTOR

terms were used: "Patient Satisfaction", "Physicians or Doctors" and "Physician/Doctor-Patient Relations", which were connected together. In the PsycINFO search, the search phrases "Patient satisfaction with the Physician" and "Patient Satisfaction with Doctor" were used. Empirical articles that were peer-reviewed and appeared in scholarly journals defined the search parameters. For both databases, English language restriction was applied. Abstracts of publications found were screened, selected and categorized by the first author (VB), utilizing the following criteria:

a) Studies must have included PS as a primary variable of interest.

b) Studies must have used a quantitative measure to assess PS. The publication must have included either the full questionnaire or a subset of its items. If the questionnaire items were not provided, then the publication must have referenced a source article which presented the items. It should be noted that in many cases, the source article that featured the PS measure was published prior to 2000.

c) The questionnaire's purpose was to explicitly measure PS. Studies using questionnaires to assess frequency of particular doctor behaviors or to assess other outcomes (e.g., effectiveness of a communication skills program) were not included.

Case reports, editorials, commentaries and research letters were excluded. As previously mentioned, the quality of the selected articles and the psychometric properties of the PS measures were not systematically evaluated.

$\underline{\text { Questionnaires in the eligible articles were "deconstructed" by one of the authors (VB); }}$ i.e., each individual item was pulled out from the questionnaire and examined. Tentative PSD domains were independently derived by two authors (VB, TH) and finalized through consensus, 
PATIENT SATISFACTION WITH DOCTOR

guided by the empirical literature on established determinants of PSD as well as existing measure subscales. Individual items were then categorized and mapped onto PSD domains. This "reconstruction" of the PSD domains was based on content similarity and existing literature. A second author $(\mathrm{TH})$ independently went through this deconstructionreconstruction process with the questionnaire items. TH also assessed the mutual exclusiveness and collective exhaustiveness of each PSD domain. Discrepancies were discussed between both authors and final categorization of items into the appropriate PSD domain was arrived at through consensus. Detailed information for the included studies was recorded in a data extraction sheet in Excel, which included the article's full citation information, the questionnaire used in the study and its reference (if applicable), the context in which PSD was realized, and the domain that each questionnaire item was mapped onto. Items that were more global in nature were defined as questions that asked patients: a) To rate an individual's overall satisfaction with their doctor (Overall Satisfaction); or b) To state if this was the individual's preferred healthcare provider (Preferred Doctor); or c) To state whether or not the individual would recommend this doctor to others (Recommendation); or d) To state the patient's intention to follow the doctor's medical advice/treatment (Intent to Follow Doctor's Advice). These global questions represented a more summative evaluation of patients' experiences with doctors and did not fall into a specific PS domain.

\section{Results}

PsycINFO and MEDLINE literature searches yielded a total of 1726 articles, of which 209 were doubly registered. There were 65 commentaries, 5 errata, 56 qualitative studies, 12 article 
PATIENT SATISFACTION WITH DOCTOR

replies, and 63 miscellaneous records (e.g., editorials, case reports, research letters). Of the remaining 1316 articles, 316 publications fulfilled study criteria described above.

PSD was realized in one of four contexts. In three contexts, questions assessing PSD were embedded in a larger questionnaire measuring PS with either: 1) Overall healthcare primarily tapping into general healthcare beliefs and attitudes; 2) A specific consultation/visit, hospitalization or medical encounter; or 3) The overall healthcare team, of which the doctor was a member. In the fourth context, the questionnaire was composed entirely of items asking about the individual's satisfaction with their particular physician. Of the articles meeting study criteria, 153 used items or measures focused solely on PSD. It should be noted that not all 153 studies used entire PS measures. In some cases, items were taken or adapted from other available PS questionnaires that were broader in scope (e.g., looking at PS with overall care). In other cases, the researchers constructed PS questions for the express purposes of the study. In the latter situation, these questions may or may not have been guided by any theoretical framework or based on available PS measures with proven psychometric properties.

Within the four contexts of the PS measures, five broad domains were revealed [see Figure 1]. Within each domain, there were frequently observed a number of specific doctor characteristics and skills, and patient perceptions. Table 1 details these subcomponents as well as their frequency of occurrence across all PS measures reviewed:

A. Communication Attributes - Questions focused on communication issues, such as the doctor's listening skills, eliciting pertinent and important patient information, providing explanations of complex medical information, and whether or not the doctor addressed all the patient's questions and concerns. 
PATIENT SATISFACTION WITH DOCTOR

B. Relational Conduct - Questions focused on perceived doctor interpersonal skills and behaviors demonstrated during the medical interaction; e.g., treating the patient with respect and seeing the patient as a "person". This category also included the doctor's professional attitude and courtesy, and inclusion of the patient as an active participant in healthcare decision-making. This category included patient-related "outcomes" arising from the doctor's relational conduct, such as developing trust, feeling understood and taken seriously.

C. Technical Skill - Questions focused on patient's perceptions of the doctor's professional knowledge and expertise.

D. Personal Qualities - Questions focused on patient's appraisal of the doctor's "humane" qualities, such as caring, sensitivity, and compassion.

E. Availability and Accessibility - Questions focused on the patient's perception of the time spent with their physician and whether or not the doctor was reachable when needed.

As shown in Table 1, the doctor characteristics that were featured most prominently in a majority of PSD measures were: Technical skill (180), Providing valued medical/health information (166), Humaneness (154), and spending adequate time with the patient so that s/he does not feel "rushed" (154).

Of the 316 relevant publications, 271 articles used measures that contained at least one PSD domain. Of these 271, 245 assessed two or more PSD domains [see Table 2 for examples of questionnaire items assessed in each domain]. Of the remaining publications, 45 used global patient evaluations, with 29 studies solely using a one-item overall PS rating (e.g., "Rate the overall care you received from your doctor/provider" using a five-point scale ranging from 
PATIENT SATISFACTION WITH DOCTOR

"Excellent" to "Poor"; "How satisfied are you with your primary care doctor?" (Very satisfied, Satisfied, Dissatisfied, Very dissatisfied)). Other global evaluation questions included: a) Recommendation (e.g., "I would recommend this doctor to others"); b) Preferred Doctor (e.g., "I would make a special effort to see this doctor in the future"); c) Intent to Follow Doctor's Advice (e.g., "I will follow the doctor's advice because I think s/he is absolutely right"). Fifteen studies used multiple global evaluations in their assessment of PSD. Of the 316 total publications, 80 studies used measures assessing domains of PS and also included one or more global evaluations. Table 3 lists examples of commonly used PS measures and the doctorrelated domains they assess.

\section{Discussion and Conclusion}

\subsection{Discussion}

The purpose of this scoping review was to determine the current state of knowledge on the conceptualization of "patient satisfaction with the doctor", based on how the construct is measured in the empirical literature. The review uncovered five broad dimensions that were prominent in most measures of PSD: a) Communication Attributes, b) Relational Conduct, c) Technical Skill, d) Personal Qualities, and e) Availability and Accessibility [see Figure 1].

The relationship the patient has with his/her doctor is a unique and potentially influential one, involving considerable reliance and trust, and whose benefits rest on the overall strength of the medical collaboration. This review revealed that the doctor's interpersonal characteristics and skills, expertise and professional demeanor frequently compose a majority of PS measures. In particular, a doctor's perceived technical skill and humaneness, providing information pertinent to a patient's healthcare, and being available appeared to be key 
PATIENT SATISFACTION WITH DOCTOR

components of PSD, as reflected by their prominence in most questionnaires. These PSD domains can facilitate a satisfactory interaction and build a positive, enduring partnership between patient and provider; Communication Attributes and Relational Conduct being prime examples. Skills underlying these two domains work synergistically to enrich the quality of the patient-doctor relationship and are essential in building a strong healthcare "partnership" $[42,67]$. Effective, open communication and willingness to work as a "team" with a patient who is engaged in their healthcare are key factors in attaining and maintaining high PS $[4,68]$.

While perceived technical proficiency is essential to PSD, results from this review show a predominance of PSD questionnaire items that focus on the "humane" part of medical care. Patients' ratings of a doctor's interpersonal qualities are salient, significant factors in determining satisfaction with their medical care $[69,70]$, as per their expectations for a "warm, caring" doctor interaction. Moreover, these qualities are often important determinants of remaining with a particular healthcare provider [71-73]. When combined with confidence in the provider's expertise, these humane skills and behaviors engender patient trust. Many medical outcomes from many caring patient-doctor interactions aggregate over time (e.g., greater patient loyalty, increased likelihood of keeping medical appointments, following doctor advice and treatment regimen) $[24,37,74,75]$. The psychological impacts are equally noteworthy, such as decreasing patient anxiety, increasing hope and optimism for treatment success/recovery, and promoting feelings of well-being $[76,77]$. Indeed, an important use of PSD measures is the identification of areas of improvement in building and maintaining a strong doctor-patient relationship [47]. 
PATIENT SATISFACTION WITH DOCTOR

This scoping review highlights the variability in aim, scope and content of available PSD measures. First, PSD can be assessed in a number of different contexts: as part of an assessment of satisfaction with overall care, or with a specific medical experience (see Table 3). Alternatively, one can assess satisfaction with the doctor as a member of a healthcare team or as an individual. Therefore, when assessing PSD, it may be helpful to limit the measure's scope to a specific healthcare episode, particularly when evaluating the quality of practice care; however, assessment goals will dictate these boundaries [28]. Second, the measure may be multidimensional, composed of a number of different domains, or be more global, with broad questions asking about overall satisfaction, willingness to recommend a doctor, or expressing a preference for a particular doctor. There is an important cautionary note to be aware of when using global evaluations of PSD. The sole use of global questionnaire items can be potentially problematic since one cannot determine exactly what aspect of care the patient is evaluating, and hence what the individual is (or is not) satisfied with. PSD is a colloquial term of our everyday medical lexicon, which can refer to a multitude of factors. Global evaluations may (or may not) be a reflection of many aspects of healthcare received, thus making these PSD ratings difficult to interpret $[23,28]$. It would be particularly beneficial for assessors whose goals are the evaluation of practice standards, or the investigation of the determinants of PSD, to adopt an assessment tool which lists specific areas for potential improvement. It has long been suggested that an ideal PSD measure should contain a combination of domains, with multiple items [28,77], plus a global evaluation [23].

A long-standing critique of many available PS measures in general is the absence of a solid theoretical framework guiding measure development $[28,54,79]$. This makes comparisons 
PATIENT SATISFACTION WITH DOCTOR

of PSD surveys across studies quite difficult [7]. In a meta-analysis of general PS measures, Hall and Dornan [78] found that many studies assessing this construct used non-standardized measures with questionable (or even non-existent) validity and reliability; a finding also obtained by a review conducted by Sitzia [80]. Moreover, many researchers developed their own questionnaire to measure PS [78]; an observation found in the present review. As aptly pointed out by many researchers in this field, a majority of investigations of PS do not have the goal of theory testing or building but rather the discovery of its sociodemographic, cultural, organizational, and other determinants $[81,82]$. While the variety and heterogeneity of PS measures may offer many options for its assessment, this can create some confusion and uncertainty due to the lack of consensus and clarity in how PS is conceptualized and hence measured [23]. This study's results illustrating the 5 domains predominating current measures of PSD is a first step towards informing the development of a comprehensive, empirically derived theoretical model of the construct.

When interpreting PSD evaluations, it is important to remember that patient ratings are partly informed by factors outside the medical encounter, particularly patient-related factors such as individual's immediate healthcare goals, the degree to which treatment expectations are successfully met, patient physical and psychological well-being [e.g., 4,28,83,84,85]. These subjective evaluations may not be wholly based on the doctor per se but the patient's own healthcare expectations, beliefs, past experiences, physical and psychological health $[85,86]$; for example, in the treatment of chronic health conditions in which a patient is resistant to lifestyle changes advocated by the doctor, or in cases where a patient may want to undergo medical tests for medically unexplained symptoms that the doctor perceives are not necessary. System 
PATIENT SATISFACTION WITH DOCTOR

and organizational issues, as well as the type of healthcare setting in which PSD is being measured (e.g., acute, primary care), can also powerfully impact PSD $[85,87]$. For example, in acute care settings in which patients may be rating their satisfaction with a doctor who is part of a healthcare team, it is possible that their rating may be influenced by the quality of coordination of care. Delays in delivery of care prescribed by the doctor may be reflected in a negative evaluation. Perhaps one last issue for consideration is the timing of assessment [88]. PSD may be conceptualized as a fluid construct, continually being re-defined and re-evaluated, not only during the medical encounter $[41,86]$, but also throughout the patient's lifetime. Forces shaping PSD, such as an individual's current health status and living circumstances, and the political and economic conditions in which these healthcare services are provided, will constantly be in a state of flux, and consequently impact satisfaction ratings.

A notable outcome from the culmination of PSD research has been the development of guidelines for healthcare provider professionalism. Physician traits and behaviors valued by patients are considered essential components of "good, standardized medical practice", and are required professional competencies in both North America and Europe [e.g., 89,90]. Thus, the assessment of PSD has significant implications for medical training. Multidimensional PSD questionnaires can point to key areas of professional development, with the goal of helping future doctors provide optimal, patient-centred care. Results of this review, however, show that the number of questionnaires completely devoted to the assessment of PSD is considerably fewer than ones focused on PS with overall care or with a specific medical encounter. Moreover, the generation of newer tools assessing PSD appears to be somewhat stagnant in the past decade; a cause of some concern, with implications for training and 
PATIENT SATISFACTION WITH DOCTOR

practice quality at the doctor-level. Psychometrically sound measures of PSD, developed with a solid theoretical foundation, are needed.

\subsection{Conclusion}

As the healthcare system's focus on patient-centered care evolves, the methods by which PS with the healthcare experience is measured will also evolve. This review suggests that satisfaction with the doctor will continue to be a central property of PS measures for the foreseeable future.

\subsection{Practice Implications}

PS ratings are widely and routinely obtained to serve a variety of purposes, such as serving as proxies for healthcare quality and as tools shaping medical education and policy development at the doctor and organizational level, guiding professional standards of care, and influencing governmental funding directives. With the great variety of measures and the growing proliferation of PS questionnaires, we felt it important to examine the current PS landscape and take stock of the plethora of measurement tools in use and the PSD domains being assessed. This scoping review thus provides an overview of measures used in the past decade. While this review's purpose was not to make recommendations on what PSD questionnaire to use, results suggest a few important cautions to be aware of when assessing this construct. First, this scoping review found that there are many PSD questionnaires in use, which vary in type and quantity of domains being assessed. In choosing any PSD measure, the reader is advised to consider the questionnaire's psychometric properties, as not all have been developed with a theoretical framework in mind and validated with scientific rigor. Second, 
PATIENT SATISFACTION WITH DOCTOR

researchers, clinicians and administrators should keep in mind that PSD measures differ in the context in which they are applicable and in the degree of specificity of the domains covered. This necessitates careful consideration of the assessors' goals when selecting a measure to use, particularly the PSD domains of interest. In some instances, administrators may want to develop their own PSD questionnaire in order to fully, and in a valid manner, assess the PSD domain specific to their clinical purpose and system needs. Moving forward, researchers and administrators may find this review informative in guiding the selection of PSD measures.

Lastly, the five emergent domains underlying PSD (Communication Attributes, Relational Conduct, Technical Skill and Knowledge, Personal Qualities, Availability and Accessibility) point to potential areas of physician training and foci for quality/service assessment. To advance the field of knowledge of this construct, healthcare professionals should begin to speak specifically to the domains of PSD. In so doing, we may improve our ability to detect and target those specific domains of satisfaction with one's doctor that warrant improvement and address important unmet needs within the individual healthcare experience.

\section{Funding.}

This work conducted by Dr. Virginia Boquiren was supported by post-doctoral funding from a Chair in Psychosocial Oncology and Supportive Care Research awarded to Dr. Thomas Hack from the Canadian Breast Cancer Foundation (Prairies/NWT Division). 
PATIENT SATISFACTION WITH DOCTOR

\section{References.}

[1] T. Freeman, Using performance indicators to improve health care quality in the public sector: a review of the literature, Health Serv M anage Res. 15 (2002) 126-37.

[2] J.M. Kupfer, E.M. Bond, Patient satisfaction and patient-centered care: Necessary but not equal, J Amer Med Assoc. 308 (2012) 139-40.

[3] E. Riiskjaer, J. Ammentorp, J.F. Nielsen, et al, Patient surveys-a key to organizational change?, Patient Educ Couns. 78 (2010) 394-401.

[4] S. Squires, Patient satisfaction: How to get it and how to keep it, Nurs Manage. April (2012) 26-32. DOI: 10.1097/01.NUMA.0000413094.39091.08

[5] B. Cliff, Excellence in patient satisfaction within a patient-centered culture, J Healthc Manag. 57 (2012) 157-9.

[6] J.K. Walker, Patient satisfaction: The past directs the way to the future, J Perinat Neonat Nurs. 20 (2006) 88-90.

[7] Health Services Research Group, A guide to direct measures of patient satisfaction in clinical practice, Can Med Assoc J. 146 (1992) 1727-40.

[8] Department of Health, Patient and Public Involvement in Health: The Evidence for Policy Implementation, Department of Health, London, 2004.

[9] Department of Health, Understanding What M atters: A Guide to Using Patient Feedback to Transform Services, Department of Health, London, 2009.

[10] Institute of Medicine, Crossing the Quality Chasm: A New Health System for the 21st Century, National Academy Press, Washington, DC, 2001. 
PATIENT SATISFACTION WITH DOCTOR

[11] E. Morrow, F. Ross, P. Grocott, et al, A model and measure for quality service user involvement in health research, Int J Consum Stud. 34 (2010) 532-9.

[12] L. Marcinowicz, S. Chlabicz, R. Grebowski, Patient satisfaction with healthcare provided by family doctors: primary dimensions and an attempt at typology, BM C Health Serv Res. 9 (2009) 63. DOI: $10.1186 / 1472-6963-9-63$

[13] M.S. Sajid, M.K. Baig, Quality of health care: an absolute necessity for public satisfaction, Int J Health Care Qual Assur. 20 (2007) 545-8.

[14] V. Senić, V. Marinković, Patient care, satisfaction and service quality in health care, Int J Consum Stud. 37 (2013) 312-9.

[15] J.A. Lucas, The satisfaction survey that matters, Am J Obstet Gynecol. June (2012) 518-22. DOI: 10.1016/j.ajog.2012.01.043

[16] U.S. Department of Health and Human Services, Report to Congress: Plan to Implement a M edicare Hospital Value-Based Purchasing Program (CMS publication): 21 November 2007, CMS Hospital Value-Based Purchasing Workgroup, Washington, DC, 2007.

[17] J.H. Hibbard, J. Stockard, M. Tusler, Hospital Performance Reports: Impact on quality, market share, and reputation, Health Aff. 24 (2005) 1150-60.

[18] M.F. Hall MF, Looking to improve financial results? Start by listening to patients, Healthc Financ M anage. 62 (2008) 76-80.

[19] D.P. Kessler, D. Mylod, Does patient satisfaction affect patient loyalty?, Int J Health Care Qual Assur. 24 (2011) 266-73. 
PATIENT SATISFACTION WITH DOCTOR

[20] K. Otani, B. Waterman, K.M. Faulkner, et al, How patient reactions to hospital care attributes affect the evaluation of overall quality of care, willingness to recommend, and willingness to return, J Healthc Manag. 55 (2010) 25-37.

[21] C. Jenkinson, A. Coulter, S. Bruster, The Picker Patient Experience Questionnaire:

development and validation using data from in-patient surveys in five countries, Int J Qual Health Care. 14 (2002) 353-8.

[22] R. Baker, A. Smith, C. Tarrant, et al, Patient feedback in revalidation: an exploratory study using the consultation satisfaction questionnaire, Br J Gen Pract. 61 (2011) e638-44. DOI: 10.3399/bjgp11X601343

[23] P.L. Hudak, J.G. Wright, The characteristics of patient satisfaction measures, Spine. 25 (2000) 3167-77.

[24] E.A. Platonova, K.N. Kennedy, R.M. Shewchuk, Understanding patient satisfaction, trust, and loyalty to primary care physicians, Med Care Res Rev. 65 (2008) 696-712.

[25] B. Leisen, M.R. Hyman, Antecedents and consequences of trust in a service provider: The case of primary care physicians, J Bus Res. 57 (2004) 990-9. DOI: 10.1016/S0148-

2963(02)00343-0

[26] L. Marcinowicz, S. Chlabicz, R. Grebowski, Understanding patient satisfaction with family doctor care, J Eval Clin Pract. 16 (2010) 712-5.

[27] B. Sahin, F. Yilmaz, K.H. Lee, Factors affecting inpatient satisfaction: Structural equation modeling, J M ed Syst. 31 (2007) 9-16.

[28] P.D. Cleary, B.J. McNeil, Patient satisfaction as an indicator of quality care, Inquiry. 25 (1988) 25-36. 
PATIENT SATISFACTION WITH DOCTOR

[29] J.E. Ware Jr., M.K. Snyder, W.R. Wright, et al, Defining and measuring patient satisfaction with medical care, Eval Program Plann. 6 (1983) 247-63.

[30] C. Laine, F. Davidoff, C.E. Lewis, et al, Important elements of outpatient care: A comparison of patients' and physicians' opinions, Ann Intern M ed. 125 (1996) 640-5.

[31] A. López, A. Detz, N. Ratanawongsa, et al, What patients say about their doctors online: A qualitative content analysis, J Gen Intern Med. 27 (2012) 685-92. DOI: 10.1007/s11606-0111958-4

[32] L. Bourke, Do people prefer general practitioners of the same sex?, Aust Fam Physician. 31 (2002) 974-6.

[33] T. Gruber, F. Frugone, Uncovering the desired qualities and behaviours of general practitioners (GPs) during medical (service recovery) encounters, J Serv M anage. 22 (2011) 491-521.

[34] J. Sitzia, N. Wood, Patient satisfaction: A review of issues and concepts, Soc Sci M ed. 45 (1997) 1829-43.

[35] H.J. Sixma, P.M.M Spreeuwenberg, M.A.A. van der Pasch, Patient satisfaction with the general practitioner: A two-level analysis, Med Care. 36 (1998) 212-29.

[36] N.M. Bendapudi, L.L. Berry, K.A. Frey, et al, Patients' perspectives on ideal physician behaviors, Mayo Clin Proc. 81 (2006) 338-44.

[37] S. Miles, S.J. Leinster,. Identifying professional characteristics of the ideal medical doctor:

The laddering technique, Med Teach. 32 (2010) 136-40.

[38] J.W. Peltier, J.A. Schibrowsky, C.R. Cochran, By now it's accepted, Mark Health Serv. 22 (2002) 29-33. 
PATIENT SATISFACTION WITH DOCTOR

[39] D.F. Spake, J.S. Bishop Jr, The impact of perceived closeness on the differing roles of satisfaction, trust, commitment, and comfort on intention to remain with a physician, Health Mark Q. 26 (2009) 1-15. DOI: 10.1080/07359680802473281

[40] G.C. Pascoe, Patient satisfaction in primary health care: A literature review and analysis, Eval Program Plann. 6 (1983) 185-210.

[41] K. Collins, P. Nicolson, The meaning of 'satisfaction' for people with dermatological problems: Reassessing approaches to qualitative health psychology research, J Health Psychol. 7 (2002) 615-29.

[42] J. Haggerty, F. Burge, J-F. Lévesque, et al, Operational definitions of attributes of primary health care: Consensus among Canadian Experts, Ann Fam M ed. 5 (2007) 336-44. DOI: $10.1370 /$ afm.682

[43] M. Hojat, D.Z. Louis, K. Maxwell, A brief instrument to measure patients' overall satisfaction with primary care physicians, Fam M ed. 43 (2011) 412-7.

[44] D.K. Heyland, D.J. Cook, G.M. Rocker, et al, The development and validation of a novel questionnaire to measure patient and family satisfaction with end-of-life care: the Canadian Health Care Evaluation Project (CANHELP) Questionnaire, Palliative M ed. 24 (2010) 682-95. DOI: $10.1177 / 0269216310373168$

[45] A. Brédart, D. Razavi, N. Delvaux, et al, A comprehensive assessment of satisfaction with care for cancer patients, Support Care Cancer. 6 (1998) 518-23.

[46] D.G. Safran, M. Kosinski, A.R. Tarlov, et al, The Primary Care Assessment Survey. Tests of data quality and measurement performance, M ed Care. 36 (1998) 728-39. 
PATIENT SATISFACTION WITH DOCTOR

[47] D.A. Loblaw, A. Bezjak, T. Bunston, Development and testing of a visit-specific patient satisfaction questionnaire: The Princess Margaret Hospital Satisfaction with Doctor Questionnaire, J Clin Oncol. 1 (1999) 1931-8.

[48] S. Saha, M. Komaromy, T.D. Koepsell, et al, Patient-physician racial concordance and the perceived quality and use of health care, Arch Intern Med. 159 (1999) 997-1004.

[49] S. Linder-Pelz, E.L. Struening, The multidimensionality of patient satisfaction with a clinic visit, J Commun Health. 10 (1983) 42-54.

[50] J.A. Hall, M. Feldstein, M.D. Fretwell, et al, Older patients' health status and satisfaction with medical care in an HMO population, Med Care. 28 (1990) 261-70.

[51] M.R. DiMatteo, R. Hays, The significance of patients' perceptions of physician conduct: A study of patient satisfaction in a family practice center, J Commun Health. 6 (1980) 18-34.

[52] G.N. Marshall, R.D. Hays, The Patient Satisfaction Questionnaire Short-Form (PSQ-18), RAND, Santa Monica, CA, 1994.

[53] R. Challenor, Southwest regional genitourinary physicians' audit group: setting regional benchmarks for patient satisfaction, Int J STD AIDS. 14 (2003) 622-4.

[54] M.H. Wolf, S.M. Putnam, S.A. James, et al, The Medical Interview Satisfaction Scale:

Development of a scale to measure patient perceptions of physician behavior, J Beh M ed. 1 (1978) 391-401.

[55] H.A. Rubin, B. Gandek, W.H. Rogers, et al, Patients' ratings of outpatient visits in different practice settings. Results from the Medical Outcomes Study, J Amer Med Assoc. 270 (1993) 835-40. 
PATIENT SATISFACTION WITH DOCTOR

[56] B. Sahin, M. Tatar, Analysis of factors affecting patient satisfaction: Focus on asthma patients, Dis M anage Health Outcomes. 14 (2006) 171-83.

[57] J.E. Ware, M.K. Snyder, W.R. Wright, Development and validation of scales to measure patient satisfaction with medical care services: Vol. 1, Part A. Review of literature, overview of methods, and results regarding construction of scales (NTIS Publication No. PB 288-329), National Technical Information Service, Springfield, VA, 1976a.

[58] J.E. Ware, M.K. Snyder, W.R. Wright, Development and validation of scales to measure patient satisfaction with medical care services: Vol. 1, Part B. Results regarding scales constructed from the Patient Satisfaction Questionnaire and measures of other health care perceptions (NTIS Publication No. PB288-330), National Technical Information Service, Springfield, VA, 1976b.

[59] D. Wilkin, L. Hallem, M. Duggett, Measures of need and outcome for primary health care, Oxford University Press, New York, 1992.

[60] R. Grol, M., Wensing, J. Mainz, et al, Patients in Europe evaluate general practice care: an international comparison, Br J Gen Pract. 50 (2000) 882-7.

[61] R. Baker, Development of a questionnaire to assess patients' satisfaction with consultations in general practice, Br J Gen Pract. 40 (1990) 487-90.

[62] A. Brédart, D. Razavi, C. Robertson, et al, A comprehensive assessment of satisfaction with care: preliminary psychometric analysis in French, Polish, Swedish and Italian oncology patients, Patient Educ Couns. 43 (2001) 243-52. 
PATIENT SATISFACTION WITH DOCTOR

[63] A. Brédart, D. Razavi, C. Robertson, et al, A comprehensive assessment of satisfaction with care: Preliminary psychometric analysis in an oncology institute in Italy. Ann Onc. 10 (1999) 839-46.

[64] N. Mead, P. Bower, M. Roland, The General Practice Assessment Questionnaire (GPAQ). Development and psychometric characteristics, BM C Fam Pract. 9 (2008) 13. DOI :10.1186/1471-2296-9-13

[65] L. Frostholm, P. Fink, E. Oernboel, et al, The uncertain consultation and patient satisfaction: The impact of patients' illness perceptions and a randomized controlled trial on the training of physician's communication skills, Psychosom M ed. 67 (2005) 897-905.

[66] D. Webster, Final report on the patient satisfaction questionnaire project, Philadelphia, PA: American Board of Internal Medicine, Philadelphia, PA, 1989.

[67] J.L. Haggerty, Measurement of primary healthcare attributes from the patient perspective, Healthc Policy. 7(2011) 13-20. DOI: 10.12927/hcpol.2011.22689

[68] G. Saba, S. Wong, D. Schillinger, et al, Shared decision making and the experience of partnership in primary care, Ann Fam M ed. 4 (2006) 54-62. DOI: 10.1370/afm.393 [69] R.M. Andersen, G.V. Fleming, L.A. Aday, The public's view as input for medical manpower planning, Socioecon Issues Health. (1981) 3-19.

[70] S.T. Wong, D.E. Watson, E. Young, et al, What do people think is important about primary healthcare?, Healthc Policy. 3 (2008) 89-104.

[71] A.G. Mainous III, R. Baker, M.M. Love, et al, Continuity of care and trust in one's physician: evidence from primary care in the United States and the United Kingdom, Fam M ed. 33 (2001) $33: 22-7$. 
PATIENT SATISFACTION WITH DOCTOR

[72] P.A. Nutting, M.A. Goodwin, S.A. Flocke, et al, Continuity of primary care: to whom does it matter and when?, Ann Fam M ed. 1 (2003) 149-55.

[73] D.G. Safran. Defining the future of primary care: what can we learn from patients?, Ann Intern M ed. 138 (2003) 248-55.

[74] M.R. Dimatteo, L.J. Prince, A. Jaranta, Patient's perceptions of physicians' behavior:

Determinants of patient commitment to the therapeutic relationship, Journal of Commun Health. 4 (1979) 280-90.

[75] B.S. Hulka, J.C. Cassel, L.C. Kupper, et al, Communication, compliance, and concordance between physicians and patients with prescribed medications, Am J Public Health. 6 (1976) 847-53.

[76] I. Press, R. Ganey, M.P. Malone, Satisfied patients can spell financial well-being. Healthc Financ M anage, 45 (1990) 34-6,38,42.

[77] J.E. Ware, How to survey patient satisfaction, Drug Intel Clin Phar. 15 (1981) 892-9.

[78] J.A. Hall, M.C. Dornan, Meta-analysis of satisfaction with medical care: Description of research domain and analysis of overall satisfaction levels, Soc Sci M ed. 27 (1988) 637-44.

[79] L. Aharony, S. Strasser, Patient satisfaction: what we know about and what we still need to explore, M ed Care Rev. 50 (1993) 49-79.

[80] J. Sitzia, How valid and reliable are patient satisfaction data? An analysis of 195 studies, Int J Qual Health Care. 11 (1999) 319-28.

[81] S. Linder-Pelz, Toward a theory of patient satisfaction, Soc Sci Med. 16 (1982) 583-9.

[82] D. Locker, D. Dunt, Theoretical and methodological issues in sociological studies of consumer satisfaction with medical care, Soc Sci Med. 12 (1978) 283-92. 
PATIENT SATISFACTION WITH DOCTOR

[83] J.L. Hopton, J.G.R. Howie, A.M.D. Porter, The need for another look at the patient in general practice satisfaction surveys, Fam Pract. 10 (1993) 82-7.

[84] H.R. Rubin HR, Patients' evaluations of hospital care: A review of the literature, M ed Care. 28 (1989) S1-9.

[85] D. Feldman-Stewart, M.D. Brundage, C. Tishelman, A conceptual framework for patientprofessional communication: An application to the cancer context, Psycho-Oncology. 14 (2005) $801-809$.

[86] S. Strasser, L. Aharony, D. Greenberger, The patient satisfaction process: Moving toward a comprehensive model, Med Care Rev. 50 (1993) 219-48.

[87] A.J.K. Péfoyo, W.P. Wodchis, Organizational performance impacting patient satisfaction in Ontario Hospitals: a multilevel analysis, BM C Res Notes 6 (2013) 509. DOI: 10.1186/1756-05006-509

[88] R.A. Carr-Hill, The measurement of patient satisfaction, J Public Health Med. 14 (1992) 236-49.

[89] CanMEDS. The CanM EDS 2005 Physician Competency Framework:

http://www.royalcollege.ca/portal/page/portal/rc/canmeds/framework Accessed 21 January 2014.

[90] General Medical Council, Good medical practice, General Medical Council, Manchester, 2013.

\section{Figure legends}

Figure 1. Principle domains assessed by measures of patient satisfaction with the doctor. 
PATIENT SATISFACTION WITH DOCTOR

Table 1. Domains assessed by patient satisfaction with the doctor measures (Total $\mathrm{N}=316$ )

\begin{tabular}{|c|c|}
\hline Domain & $\begin{array}{l}\text { Total number of } \\
\text { articles }\end{array}$ \\
\hline A. Communication Attributes & \\
\hline A1. Listening skills & 95 \\
\hline A2. Eliciting patient information & 19 \\
\hline A3. Providing explanations & 92 \\
\hline A4. Ensuring patient understanding & 38 \\
\hline A5. Providing information & 166 \\
\hline A6. Addressing patient's concerns and questions & 50 \\
\hline Broad evaluation of communication & 26 \\
\hline \multicolumn{2}{|l|}{ B. Relational Conduct } \\
\hline B1. Treating patient with respect & 121 \\
\hline B2. Professional demeanor & 82 \\
\hline B3. Allowed patient a shared role in medical care and decision making & 52 \\
\hline B4. Patient trust and confidence & 82 \\
\hline B5. Patient felt understood and heard & 44 \\
\hline $\begin{array}{l}\text { B6. Patient felt that } \mathrm{s} / \text { he and/ or her/ his health problem were taken } \\
\text { seriously }\end{array}$ & 54 \\
\hline Broad evaluation of relational conduct & 27 \\
\hline C. Technical Skill & \\
\hline C1. Professional knowledge and expertise & 180 \\
\hline D. Personal Qualities & \\
\hline $\begin{array}{l}\text { D1. “Humaneness” (Empathy, Sensitivity, Concern, Caring, Friendliness, } \\
\text { Kindness) }\end{array}$ & 154 \\
\hline E. Availability and Accessibility & \\
\hline
\end{tabular}


PATIENT SATISFACTION WITH DOCTOR

\begin{tabular}{|l|c|}
\hline E1. Patient did not feel rushed; Spent adequate time with physician & 154 \\
\hline E2. Doctor was accessible. & 33 \\
\hline Broad evaluation of accessibility & 4 \\
\hline
\end{tabular}




\section{PATIENT SATISFACTION WITH DOCTOR}

Table 2. Questionnaire examples of domains assessed by patient satisfaction with the doctor measures.

\begin{tabular}{|c|c|c|}
\hline Domain & & Example of questionnaire item \\
\hline \multirow[t]{5}{*}{$\begin{array}{l}\text { A. Communication } \\
\text { Attributes }\end{array}$} & 1. Listening skills & $\begin{array}{l}\text { "My doctor listens carefully to me" (PSS) [43] } \\
\text { "How satisfied are you that the doctor(s) listened to what you had to } \\
\text { say during the past month?" (CANHELP) [44] }\end{array}$ \\
\hline & 2. Eliciting patient information & $\begin{array}{l}\text { "Concerning doctors, how would you rate: the questions they asked } \\
\text { you about your physician problems?" (CASC SF 4.0) [45] } \\
\text { [Rate] "Thoroughness of doctor's questions about your symptoms } \\
\text { and how you are feeling" (PCAS) [46] } \\
\text { "My doctor encourages me to talk about all my health concerns" } \\
\text { (PSS) [43] }\end{array}$ \\
\hline & 3. Providing explanations & $\begin{array}{l}\text { "The doctor used words I did not understand" (PMH/PSQ-MD) [47] } \\
\text { "My doctor explains things in a way that is easy for me to } \\
\text { understand" (PSS) [43] }\end{array}$ \\
\hline & $\begin{array}{l}\text { 4. Ensuring patient } \\
\text { understanding }\end{array}$ & $\begin{array}{l}\text { "How would you rate your regular physician on the job he/she is } \\
\text { doing in: Making sure you understand what you have been told } \\
\text { about your medical problems or medication?" [48] } \\
\text { "I understand my illness much better after seeing this doctor" } \\
\text { (PMH/PSQ-MD) [47] }\end{array}$ \\
\hline & 5. Providing Information & $\begin{array}{l}\text { "The doctor should have told me more about how I can take care of } \\
\text { my condition" [49] } \\
\text { "My healthcare providers have explained completely the reasons for }\end{array}$ \\
\hline
\end{tabular}




\section{PATIENT SATISFACTION WITH DOCTOR}

\begin{tabular}{|c|c|c|}
\hline & & examination procedures or medical tests" [50] \\
\hline & $\begin{array}{l}\text { 6. Addressing patient's } \\
\text { concerns and questions }\end{array}$ & $\begin{array}{l}\text { "There are some health issues that I feel my health care providers } \\
\text { have not given enough attention to" [50] } \\
\text { "The doctor seemed to brush off my questions" (PMH/PSQ-MD) [47] }\end{array}$ \\
\hline \multirow[t]{6}{*}{$\begin{array}{l}\text { B. Relational } \\
\text { Conduct }\end{array}$} & 1. Treating patient with respect & $\begin{array}{l}\text { "This doctor always treats me with a great deal of respect and never } \\
\text { 'talks down' to me" [51] } \\
\text { "My health care providers have always treated me with utmost } \\
\text { respect" [50] } \\
\text { "Concerning doctors, how would you rate: the interest they showed } \\
\text { in you personally and not just in your illness?" (CASC SF 4.0) [45] }\end{array}$ \\
\hline & 2. Professional demeanor & $\begin{array}{l}\text { "Doctors act too businesslike and impersonal toward me" (PSQ-18) } \\
\text { [52] }\end{array}$ \\
\hline & $\begin{array}{l}\text { 3. Allowed patient a shared } \\
\text { role in medical care and } \\
\text { decision-making }\end{array}$ & "Did you feel involved in decisions about your care?" (CSS) [53] \\
\hline & 4. Patient trust and confidence & $\begin{array}{l}\text { "The doctor I saw today would be someone I would trust with my } \\
\text { life" (MISS) [54] } \\
\text { "I have a great deal of confidence in this doctor" [51] }\end{array}$ \\
\hline & $\begin{array}{l}\text { 5. Patient felt understood and } \\
\text { heard }\end{array}$ & $\begin{array}{l}\text { "I really felt understood by my doctor" (MISS; PMH/PSQ-MD) } \\
{[47,54]} \\
\text { “I felt that this doctor didn't take my problems very seriously" (MISS) } \\
{[54]}\end{array}$ \\
\hline & $\begin{array}{l}\text { 6. Patient felt that s/he and/or } \\
\text { health nrohlem were taken }\end{array}$ & 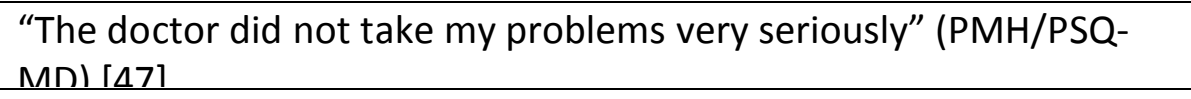 \\
\hline
\end{tabular}




\begin{tabular}{|c|c|c|}
\hline & $\begin{array}{l}\text { health problem were taken } \\
\text { seriously }\end{array}$ & MD) [47] \\
\hline C. Technical Skill & $\begin{array}{l}\text { 1. Professional knowledge and } \\
\text { expertise }\end{array}$ & $\begin{array}{l}\text { "How would you rate: The technical skills (thoroughness, } \\
\text { carefulness, competence) of the person you saw" (MOS 9-item VRQ) } \\
\text { [55] } \\
\text { "I believe that my doctor is competent and knowledgeable" [56] } \\
\text { "Some of the doctors I have seen lack experience with my medical } \\
\text { problems" (PSQ-III) [57-59] }\end{array}$ \\
\hline $\begin{array}{l}\text { D. Personal } \\
\text { Qualities }\end{array}$ & $\begin{array}{l}\text { 1. "Humaneness" (Empathy, } \\
\text { Sensitivity, Concern, Caring, } \\
\text { Friendliness, Kindness) }\end{array}$ & $\begin{array}{l}\text { "How satisfied are you that the doctors and nurses looking after you } \\
\text { during the past month were compassionate and supportive?" } \\
\text { (CANHELP) [44] } \\
\text { [Rate] "Doctor's caring and concern for you" (PCAS) [46] } \\
\text { "My doctor treated me in a very friendly and courteous manner" } \\
\text { (PSQ-18) [52] } \\
\text { "This doctor is always very kind and very considerate of my feelings" } \\
\text { [51] }\end{array}$ \\
\hline \multirow[t]{2}{*}{$\begin{array}{l}\text { E. Availability \& } \\
\text { Accessibility }\end{array}$} & $\begin{array}{l}\text { 1. Patient did not feel rushed; } \\
\text { Spent adequate time with } \\
\text { physician }\end{array}$ & $\begin{array}{l}\text { "I feel the doctor did not spend enough time with me" (MISS) [54] } \\
\text { "The doctor seemed rushed today" (PMH/PSQ-MD) [47] }\end{array}$ \\
\hline & 2. Physician was accessible & $\begin{array}{l}\text { "How satisfied are you that your doctor(s) were available when you } \\
\text { needed them (by phone or in person) during the past month? } \\
\text { (CANHELP) [44] } \\
\text { "If I have a medical question, I can reach a doctor for help without } \\
\text { any problem" (PSQ-III) [57-59] }\end{array}$ \\
\hline
\end{tabular}




\section{PATIENT SATISFACTION WITH DOCTOR}

Note: CANHELP = Canadian Health Care Evaluation Project Patient Questionnaire; CASC SF 4.0 = Comprehensive Assessment of Satisfaction with Care; CSS = Consultation Satisfaction Survey; MISS = Medical Interview Satisfaction Scale; MOS 9-item VRQ = Medical Outcomes Study 9-item Patient Visit Rating Questionnaire; PSQ-III = Long-Form Patient Satisfaction Questionnaire; PSQ-18 = Short-Form Patient Satisfaction Questionnaire; PCAS = Primary Care Assessment Survey; PSS = Patient Satisfaction Scale; PMH/PSQ$M D=$ Princess Margaret Hospital Patients Satisfaction with Doctor Questionnaire 
PATIENT SATISFACTION WITH DOCTOR

Table 3. Examples of measures assessing patient satisfaction with the doctor.

\begin{tabular}{|c|c|c|}
\hline Group & Measure & Physician-related domains assessed \\
\hline $\begin{array}{l}\text { Satisfaction with Overall } \\
\text { Care (with subset } \\
\text { assessing satisfaction } \\
\text { with doctor) }\end{array}$ & $\begin{array}{ll}\text { 1. } & \text { CANHELP }{ }^{\mathrm{a}}[44] \\
\text { 2. } & \text { EUROPEP [60] } \\
\text { 3. } & \text { PSQ-III [57-59] } \\
\text { 4. } & \text { PSQ-18 [52] } \\
\text { 5. } & \text { PCAS [46] }\end{array}$ & 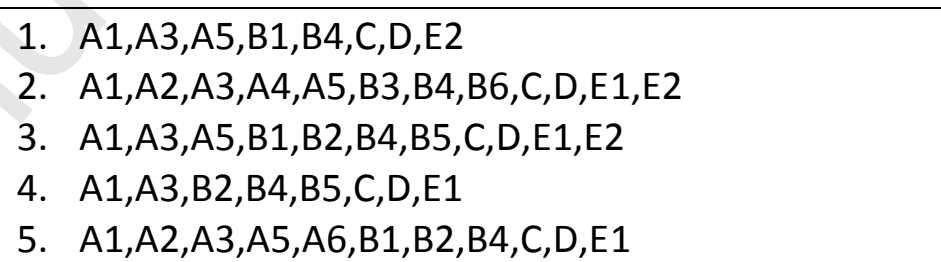 \\
\hline $\begin{array}{l}\text { Satisfaction with } \\
\text { Consultation-Visit or } \\
\text { Hospitalization (with } \\
\text { subset assessing } \\
\text { satisfaction with doctor) }\end{array}$ & $\begin{array}{l}\text { 1. CSQ [61] } \\
\text { 2. CASC SF } 4.0^{\mathrm{b}}[45,62,63] \\
\text { 3. } \text { CAHPS }^{\circledR} \text { Clinician \& Group Surveys - Visit } \\
\text { Survey } 2.0^{\mathrm{c}} \\
\text { 4. GPAQ-R [64] } \\
\text { 5. MOS 9-item VRQ [55] } \\
\text { 6. PSCQ-7[65] } \\
\text { 7. PSQ [49] } \\
\text { 8. PPEQ-15 }{ }^{\mathrm{d}}[21]\end{array}$ & $\begin{array}{l}\text { 1. A5,B1,B4,C,E1 + Global Evaluation: Intention to } \\
\text { Follow Physician's Advice } \\
\text { 2. A1,A2,A5,B1,C,D,E1,E2 } \\
\text { 3. A1,A3,A5,B1,C,E1 + Global Evaluation: Overall } \\
\text { Satisfaction and Recommendation } \\
\text { 4. A1,A3,B2,B3,B4,C,D,E1 + Global Evaluation: } \\
\text { Preferred Physician } \\
\text { 5. A3,B1,C,D,E1 } \\
\text { 6. A3,B6,C } \\
\text { 7. A3,A5,A6,B1,B2,B5,B6,C + Global Evaluation: } \\
\text { Overall Satisfaction, Preferred Physician } \\
\text { 8. A3,A5,A6,B1,B3,E2 }\end{array}$ \\
\hline $\begin{array}{l}\text { Satisfaction with } \\
\text { Healthcare } \\
\text { Providers/ Team }\end{array}$ & 1. Patient Satisfaction questionnaire [50] & $\begin{array}{l}\text { 1. A1,A5,B1,B4,C,D,E1 + Global Evaluation: Overall } \\
\text { Satisfaction }\end{array}$ \\
\hline Satisfaction with Doctor & $\begin{array}{l}\text { 1. } \mathrm{ABIM}^{\mathrm{e}}[66] \\
\text { 2. } \mathrm{MISS}^{\mathrm{f}}[54] \\
\text { 3. } \mathrm{PSS}[43] \\
\text { 4. } \mathrm{PMH/PSQ}-\mathrm{MD}^{\mathrm{g}}[47]\end{array}$ & $\begin{array}{ll}\text { 1. } & \mathrm{A} 1, \mathrm{~A} 2, \mathrm{~A} 3, \mathrm{~A} 4, \mathrm{~A} 5, \mathrm{~B} 1, \mathrm{~B} 2, \mathrm{~B} 3, \mathrm{~B} 5, \mathrm{~B} 6, \mathrm{D}, \mathrm{E} 1, \mathrm{E} 2 \\
\text { 2. } & \mathrm{A} 3, \mathrm{~A} 5, \mathrm{~B} 1, \mathrm{~B} 4, \mathrm{~B} 5, \mathrm{~B} 6, \mathrm{C}, \mathrm{D}, \mathrm{E} 1 \\
\text { 3. } & \mathrm{A} 1, \mathrm{~A} 2, \mathrm{~A} 3, \mathrm{~A} 5, \mathrm{~B} 1, \mathrm{C}, \mathrm{D}, \mathrm{E} 1+\text { Global Evaluations: } \\
& \text { Overall Satisfaction, Preferred Physician } \\
\text { 4. } & \mathrm{A} 1, \mathrm{~A} 3, \mathrm{~A} 5, \mathrm{A6}, \mathrm{B} 1, \mathrm{~B} 2, \mathrm{~B} 5, \mathrm{~B} 6, \mathrm{C}, \mathrm{D}, \mathrm{E} 1, \mathrm{E} 2+\text { Global } \\
& \text { Evaluations: Recommendation, Intention to Follow }\end{array}$ \\
\hline
\end{tabular}


Note: ${ }^{a}$ The CANHELP questionnaire was designed to assess satisfaction with end-of-life care.

${ }^{\mathrm{b}}$ The CASC SF 4.0 was developed to assess satisfaction with hospital care for an oncology population

${ }^{\mathrm{C}} \mathrm{CAHPS}^{\circledR}$ Clinician and Group Surveys - Visit Survey 2.0 developed by the CAHPS ${ }^{\circledR}$ Consortium and The Agency for Healthcare Research and Quality

'The PPEQ-15 is a measure of patients' experiences with in-patient care.

${ }^{\mathrm{e}} \mathrm{ABIM}$ developed to measure the relationship between patients and doctors in internal medicine residencies.

fThe MISS measures patient satisfaction with a particular doctor-patient interaction, rather than general attitudes toward doctors. ${ }^{\mathrm{g}}$ The PMH/PSQ-MD was designed to be used as an outpatient satisfaction questionnaire specific to the patient-doctor interaction for an oncology population.

Note: $\mathrm{ABIM}=$ American Board of Internal Medicine; CANHELP = Canadian Health Care Evaluation Project Patient Questionnaire; CSQ = Consultation Satisfaction Questionnaire; CASC SF 4.0 = Comprehensive Assessment of Satisfaction with Care; GPAQ-R = The General Practice Assessment Questionnaire-R; MISS = Medical Interview Satisfaction Scale; MOS 9-item VRQ = Medical Outcomes Study 9-item Patient Visit Rating Questionnaire; PCAS = Primary Care Assessment Survey; PPEQ-15 = The Picker Patient Experience Questionnaire-15; PSCQ-7 = The Patient Satisfaction Consultation Questionnaire-7; PSQ-III = Long-Form Patient Satisfaction Questionnaire; PSQ = Patient Satisfaction Questionnaire; PSS = Patient Satisfaction Scale; PMH/PSQ-MD = Princess Margaret Hospital Patients Satisfaction with Doctor Questionnaire 


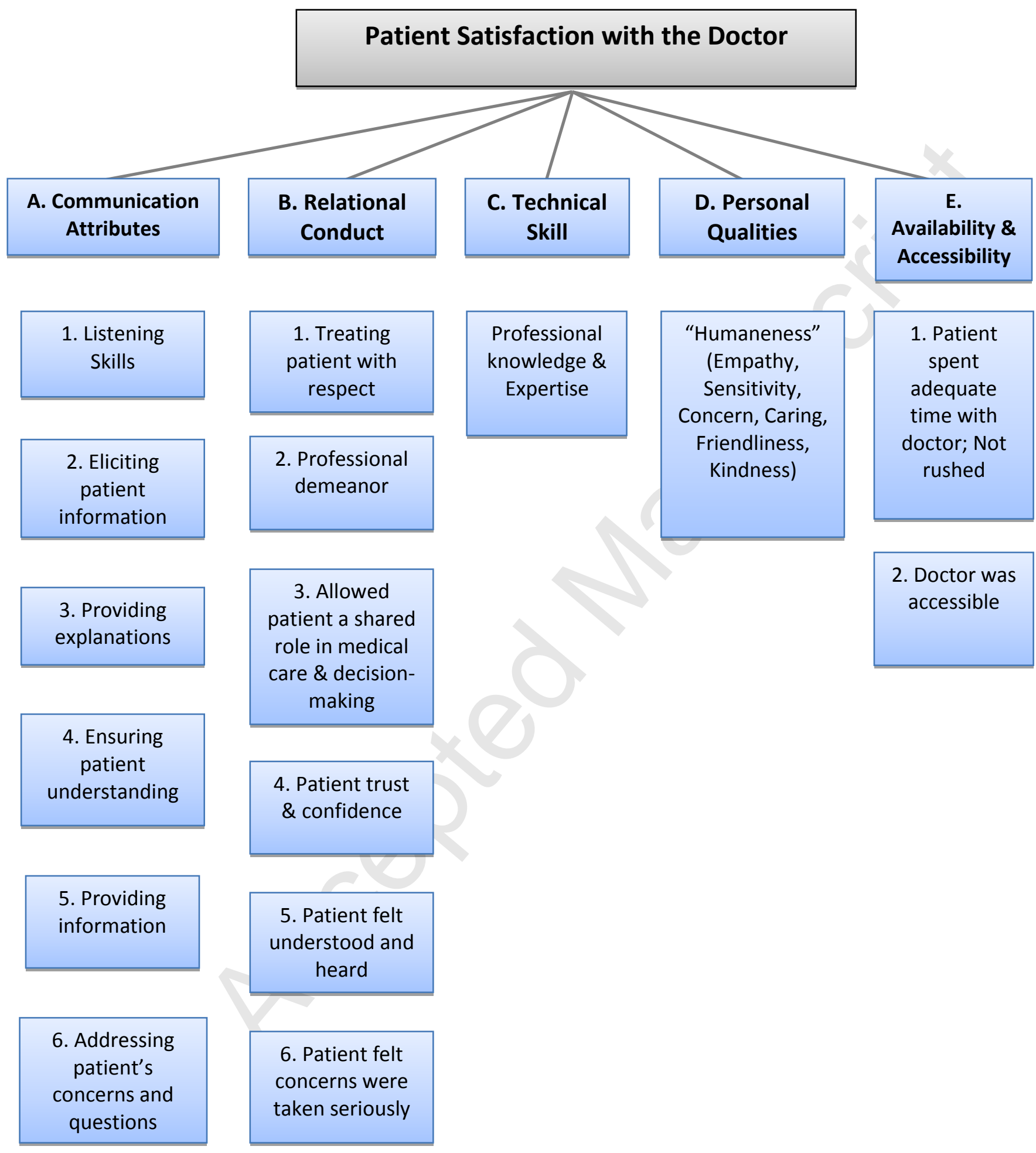

\section{Figure 1}

